\title{
Expressão das proteínas BCL-2 e BAX em tumores astrocíticos humanos
}

\section{Expression of $B C L-2$ and $B A X$ proteins in human astrocytic tumors}

Mário Henrique Girão Faria'; Régia Maria do Socorro Vidal do Patrocínio²; Manoel Odorico de Moraes Filho ${ }^{3}$; Silvia Helena Barem Rabenhorst ${ }^{4}$

\begin{abstract}
unitermos Astrocitomas

BCL-2

BAX

Apoptose

Imuno-histoquimica

\section{resumo}

Introdução: Os astrocitomas constituem os mais freqüentes tumores primários do sistema nervoso central (SNC). Admite-se que parte do crescimento tumoral seja resultante da inibição da morte celular programada: a apoptose. Tal fenômeno é basicamente regulado pelo equilíbrio entre moléculas antiapoptóticas (ex.: B-cell lymphoma protein 2 [BCL-2]) e pró-apoptóticas (ex.: BCL-2 associated protein X [BAX]). Objetivo: $O$ presente estudo objetivou avaliar a expressão de BCL-2 e BAX em tumores astrocíticos humanos. Material e métodos: Procedeu-se ao estudo imuno-histoquímico dessas proteínas utilizando-se o método da avidina-biotina-peroxidase em 55 astrocitomas (13 do grau I, 14 do II, sete do III e 21 do grau IV) e cinco amostras de tecido cerebral não-tumoral (grupo controle). Resultados: Os índices de positividade para BCL-2 e BAX demonstraram propensão ao acréscimo, de acordo com a gradação tumoral, com positividade geral de $43,26 \%$ e $24,67 \%$, respectivamente. Essas proteínas não foram detectadas entre os espécimes não-tumorais. Os escores de marcação para BCL-2 apresentaram tendência ao aumento conforme a progressão histológica, enquanto os para BAX mostraram-se semelhantes nas diversas graduações. A análise conjunta dessas proteínas demonstrou significativa correlação com a gradação tumoral $(p<$ 0,05 ; teste $\mathrm{H}$ ), sendo mais evidente nos glioblastomas ( grau IV) em comparação com os astrocitomas de baixo grau (I e II) $(p<0,05$; teste U). A relação BCL-2/BAX indicou o aumento da orientação à sobrevida celular dos tumores astrocíticos de acordo com a progressão maligna. Conclusões: Tais resultados indicam as alterações na expressão das proteínas BCL-2 e BAX como resultantes do processo tumorigênico nos astrocitomas, com o crescente predomínio do perfil antiapoptótico de acordo com a transformação maligna. Nesse sentido, sugere-se que a superexpressão de BCL-2 nos tumores astrocíticos possa ser indicativa de fenótipos mais agressivos, configurando ainda um potencial alvo terapêutico.
\end{abstract}

abstract

Background: Astrocytomas represent the most frequent primary tumors of the central nervous system. Admittedly, part of tumor growth is due to inhibition of programmed cell death: the apoptosis. This phenomenon is basically regulated by the balance between anti-apoptotic (e.g.: B-cell lymphoma protein 2 [BCL-2]) and pro-apoptotic (e.g.: $B C L-2$ associated protein $X[B A X]$ ) molecules. Objective: The present study aimed to evaluate the expression of $B C L-2$ and $B A X$ in human astrocytic tumors of different histopathological grades. Material and Method: An immunohistochemical study of those proteins using the avidin-biotin-peroxidase method was performed in 55 astrocytomas (13 grade I, 14 grade II, seven grade III and 21 grade IV) and five samples of non-tumor brain tissue (control group). Results: The BCL-2 and BAX positive indices tended to increase according to astrocytomas graduation, with general positivity of $43.26 \%$ and $24.67 \%$, respectively. These proteins were not detected among non-tumor specimens. BCL-2 labeling scores demonstrated a tendency to increase in accordance with histopathological advancing, while $B A X$ values were similar in all graduations. The combined analyses of these proteins expression presents a significant correlation with tumor grade ( $p<0.05 ; \mathrm{H}$ test), witch is more evident among glioblastomas (grade IV) in comparison with low-grade astrocytomas (I and II) ( $p<0.05 ; U$ test). BCL-2/BAX ratio denoted increasing of cellular survival orientation of the astrocytic tumors according to malignant progression. Conclusions: The results indicate alterations in BCL-2 and BAX proteins expression as resultant of the tumorigenic process in astrocytomas, with increasing predominance of the anti-apoptotic profile in consonance of malignant transformation. In this way, we propose that BCL-2 overexpression in astrocytic tumors may be indicative of more aggressive phenotypes, furthermore configuring a potential therapeutic target. key words

Astrocytomas

$B C L-2$

$B A X$

Apoptosis

Immunohistochemistry

1. Médico; mestre em Farmacologia; pesquisador do Laboratório de Cenética Molecular (LABCEM) da Universidade Federal do Ceará (UFC)

2. Médica patologista pelo Departamento de Patologia e Medicina Legal da Faculdade de Medicina (DPML/FM) da UFC; patologista do Laboratório Biomédica, Pesquisas e Serviços Ltda. (BIOPSE) (Fortaleza-CE); membro da Sociedade Brasileira de Patologia (SBP).

3. Médico oncologista; doutor em Farmacologia; professor-adjunto do Departamento de Fisiologia e Farmacologia da FMUFC; coordenador do Laboratório de Oncologia Experimental (LOE) da UFC. 4. Bióloga; doutora em Cenética; professora-adjunta do DPML da Faculdade de Medicina da UFC; coordenadora do LABCEM/UFC.

Artigo baseado na dissertação de mestrado Estudo imuno-histoquímico das alteraç̧ées moleculares nos tumores astrocíticos: vias tumorigênicas e indicadores de resistência apresentada na Faculdade de Medicina da UFC, em 2005. Trabalho selecionado para apresentação oral/premiação no XXV Congresso Brasileiro de Patologia, Natal-RN, 12 a 15 de outubro de 2005. 


\section{Introdução}

Os astrocitomas constituem o principal tipo histológico entre os tumores primários do sistema nervoso central (SNC). Na classificação histopatológica da Organização Mundial da Saúde (OMS) para os tumores próprios do SNC, admite-se que as diversas apresentações histológicas dos astrocitomas possam ser divididas em diferentes graus de malignidade, variando de I a IV ${ }^{(13)}$. Em grande parte, essa graduação resulta do reconhecimento de indicadores de anaplasia (atipia nuclear, pleomorfismo, atividade mitótica, hiperplasia endotelial e necrose) típicos de cada variante tumoral através da análise histológica rotineira por microscopia ótica. Como regra geral, o grau tumoral é baseado nas áreas de maior atipia, admitindo-se que essa população de células é a que determina o curso da doença. Além de manifestar o comportamento biológico tumoral, permitindo inferências prognósticas, o acúmulo de achados anaplásicos parece refletir a progressão das alterações moleculares adquiridas durante o processo de transformação neoplásica ${ }^{(17)}$.

A despeito da complexidade de tais desordens moleculares, elas parecem convergir para a promoção do crescimento tumoral através do estímulo à proliferação celular e/ou da inibição da morte celular, notadamente do mecanismo programado: a apoptose. $\mathrm{O}$ fato de os tumores astrocíticos humanos apresentarem, via de regra, baixos índices proliferativos em relação às outras neoplasias desperta o interesse pela determinação do status apoptótico nesses tumores ${ }^{(7)}$. Dessa forma, admite-se que o estudo dos reguladores da apoptose possa desvendar alguns aspectos enigmáticos acerca do processo de tumoração e da progressão dos astrocitomas, revelando ainda novas possibilidades terapêuticas.

Os eventos bioquímicos responsáveis pela apoptose dependem de uma família de proteases denominadas caspases, as quais são sintetizadas a partir de seus precursores inativos, ou procaspases. Uma vez ativadas, as caspases clivam (e assim ativam) outras procaspases, resultando na amplificação da cascata proteolítica. Esse mecanismo, além de destrutivo e autopropagado, é também irreversível(1).

A ativação das caspases pode ser deflagrada através de estímulos intra e/ou extracelulares. Células normais, como os linfócitos T killer, podem induzir a apoptose de células tumorais pela produção de FAS (também conhecido por APO-1, de apoptosis inducing protein 1), um ligante específico dos receptores CD95. A ligação FAS-CD95 ativa o receptor, que se acopla à proteína FAS-associated death domain (FADD), uma carreadora da procaspase iniciadora tipo 8. Essa interação permite a liberação das procaspases, que, após sofrerem auto-ativação, desencadeiam a liberação de caspases executoras ${ }^{(20)}$.

A caspase-8 também pode ativar proteínas pró-apoptóticas que promovem a formação de poros na membrana externa mitocondrial, denominada fenômeno mitochondrial-outer-membrane permeabilization (MOMP). Isso ativa a liberação do citocromo $\mathrm{C}$ no citoplasma, o qual, associado ao apoptotic protease-activating factor 1 (APAF1) e à procaspase-9, forma o chamado apoptossomo. Na presença de trifosfato de adenosina (ATP), a procaspase-9 é ativada, levando à liberação em cadeia de caspases executoras, incluindo a caspase-3(2).

As proteínas intracelulares que regulam diretamente o processo de ativação das caspases constituem a denominada família $B C L-2^{(5,6)}$. Os membros dessa família podem ser divididos em moléculas pró-apoptóticas (BAX, BAK, BCL- $\mathrm{S}_{S^{\prime}}$ $B A D, B I D, B I K, H R K, B I M$ e BOK) e antiapoptóticas (BCL2, BCL- $\mathrm{L}_{L}, \mathrm{BCL}-\mathrm{W}, \mathrm{BFL}-1, \mathrm{BRSAG}-1, \mathrm{MCL}-1, \mathrm{~A} 1, \mathrm{E} 1 \mathrm{~B} 19 \mathrm{~K}$, LMW5-HL e EBV BHRF1). O equilibro relativo entre as diferentes proteínas, refletindo a formação de homodímeros $\mathrm{e}$ heterodímeros (neutralização), define a via de atuação sobre o mecanismo de morte celular programada ${ }^{(25)}$.

A BCL-2 associated protein X (BAX), codificada pelo gene localizado na região cromossômica 19q13.3-q13.4, representa o protótipo das proteínas pró-apoptóticas. Na presença de um sinal apoptótico, a BAX é translocada do citoplasma para as proximidades das mitocôndrias, onde sofre ativação e modificação conformacional, aderindo à membrana mitocondrial externa. Pequenas unidades de proteínas BAX ativadas tendem ao agrupamento, formando oligômeros que acabam por penetrar a membrana mitocondrial externa. Essa integração possibilita a rápida liberação do citocromo $\mathrm{C}^{(3)}$.

Por outro lado, a B-cell lymphoma protein 2 (BCL-2), codificada pelo gene localizado no cromossomo 18q21, favorece a sobrevida celular. Ela impede o escape do citocromo c, possivelmente pela formação de heterodímeros com moléculas pró-apoptóticas como a proteína BAX ${ }^{(2)}$.

Nesse contexto, a presente investigação objetivou avaliar a expressão de genes reguladores da apoptose (BCL-2 e BAX) em tumores astrocíticos humanos de diferentes graduações histopatológicas (segundo a OMS).

\section{Material e métodos}

\section{Casuística}

Realizou-se levantamento dos tumores astrocíticos humanos fixados em formalina e incluídos em parafina pro- 
venientes do arquivo do Laboratório Biomédica, Pesquisas e Serviços Ltda. (BIOPSE ${ }^{\circledR}$ ), em Fortaleza, Ceará, referentes aos exames histopatológicos rotineiros realizados no período entre 1999 e 2003. Admitiram-se como critérios de inclusão a existência de mais de uma amostra (bloco) para cada caso, o bom estado de conservação dos blocos e a adequação da graduação histológica utilizada quando do diagnóstico em relação à padronizada pela $\mathrm{OMS}^{(13)}$. Dessa forma, 55 astrocitomas foram selecionados: 13 do grau I, 14 do II, sete do III e 21 do grau IV, configurando uma amostragem não-probabilística.

Como parâmetro de normalidade, cinco amostras de tecido cerebral não-tumoral fixadas em formalina e incluídas em parafina foram obtidas do material de rotina do Setor de Necropsia do Departamento de Patologia e Medicina Legal da Faculdade de Medicina da Universidade Federal do Ceará (FMUFC). Foram selecionados casos em que a causa imediata da morte e a doença de base em nada remetessem à presença de neoplasia intra ou extracerebral.

A coleta das amostras foi autorizada pelos responsáveis de cada instituição, sendo o projeto de pesquisa aprovado pelo comitê de ética em pesquisa do complexo hospitalar da UFC sob protocolo 32/04, dentro das normas que regulamentam a pesquisas em seres humanos segundo as Resoluções nos 196/96 e 251/97 do Conselho Nacional de Saúde do Ministério da Saúde (CNS/MS).

\section{Preparo das lâminas e dos cortes histológicos}

Procedeu-se à manufatura de cortes histológicos a $5 \mu \mathrm{m}$ em lâminas tratadas com silano a 4\%. Uma lâmina de cada bloco foi destinada à coloração por hematoxilina e eosina para reavaliação histopatológica e as restantes, para o estudo proteômico in situ (imuno-histoquímica).

\section{Reação imuno-histoquímica}

No presente ensaio foram estudadas as proteínas $B C L-2$ e BAX através dos anticorpos primários BCL2 (clone 124 - DakoCytomation ${ }^{\circledR}$, EUA; diluição 1:80) e BAX (policlonal - DakoCytomation ${ }^{\circledR}$, EUA; diluição 1:400). Utilizou-se o método imuno-histoquímico da estreptoavidinabiotina-peroxidase (SABP) modificado ${ }^{(11)}$, constando de: a) passagem das lâminas em estufa pré-aquecida a $60^{\circ} \mathrm{C}$ por 120 minutos; b) desparafinização e hidratação em gradiente xileno/álcool/água; c) bloqueio da peroxidase endógena com peróxido de hidrogênio $\left(\mathrm{H}_{2} \mathrm{O}_{2}\right)$ a 3\%; d) recuperação antigênica em forno de microondas utilizando tampão ci- trato $10 \mathrm{mM} \mathrm{pH}=6\left( \pm 99^{\circ} \mathrm{C}\right)$ por 15 minutos; e) incubação das lâminas com o anticorpo primário $\left( \pm 4^{\circ} \mathrm{C}\right)$ por 16 horas; f) detecção pelo sistema LSAB+ (DakoCytomation ${ }^{\circledR}$, EUA); g) revelação pelo sistema $\mathrm{DAB}+\left(\right.$ DakoCytomation $\left.^{\circledR}, \mathrm{EUA}\right)$, conforme orientações do fabricante; $h$ ) contracoloração com hematoxilina de Harrys a 40\%; i) desidratação em gradiente água/álcool/xileno, montagem com lamínula e bálsamo do Canadá.

\section{Análise imuno-histoquímica}

A avaliação imuno-histoquímica, bem como a revisão histopatológica, foi realizada por três analistas experientes de forma independente. Os eventuais resultados conflitantes foram discutidos pelos mesmos em conjunto para definição consensual da análise.

Considerou-se marcação a coloração distinta em marrom (castanho) no citoplasma celular em contraposição ao azul/ violeta da contracoloração (hematoxilina). A expressão dos marcadores foi quantificada através da contagem manual por microscopia ótica de pelo menos mil células astrocíticas, em diferentes campos representativos, utilizando magnificação de 400x. Procedeu-se então ao cálculo do labelling index $(\mathrm{LI})^{(16)}$, segundo a fórmula:

LI $(\%)=$ (número de células imunopositivas)/(número total de células contadas) $\times 100$

Admitiu-se como critério de positividade a presença dos antígenos pesquisados em no mínimo 5\% das células analisadas ( $L I \geq 5$ ). Realizou-se também contagem semiquantitativa da mesma amostragem celular, levando-se em consideração a intensidade de marcação. Foram atribuídos os valores 0 (ausente), 1+ (fraca), 2+ (moderada) e 3+ (intensa), de acordo com a intensidade observada. Tais valores configuram índices aos quais foram multiplicados os valores percentuais (\%) da fração de células que representam a respectiva categoria de intensidade, sendo calculado o $\mathrm{H}$-score $e^{(19)}$ :

$$
\text { H-score }=(\% 0) \times 0+(\% 1+) \times 1+(\% 2+) \times 2+(\% 3+) \times 3 .
$$

\section{Análise estatística}

Os escores referentes à análise imuno-histoquímica foram tabulados utilizando-se o programa SPSS ${ }^{\circledR}$ 13.0. Os dados foram comparados através de abordagens não-paramétricas (teste de Shapiro-Wilk, teste $\mathrm{H}$ de Kruskal-Wallis e teste $U$ de Mann-Whitney), sendo os resultados expressos como média \pm 2 desvios padrão da média (DPM). Foram considerados significativas valores de $p<0,05$. 


\section{Resultados}

Exemplos de reações imuno-histoquímicas para BCL-2 e BAX estão ilustrados na Figura 1 e a Tabela apresenta detalhadamente os resultados obtidos. O percentual de casos que demonstraram imunoexpressão da proteína BCL-2 aumentou conforme a malignidade dos tumores astrocíticos (23,07\% no grau I; $35,71 \%$ no II; $42,86 \%$ no III; $71,43 \%$ no IV). A expressão da proteína BAX mostrou semelhante tendência $(15,38 \% ; 7,14 \% ; 28,57 \% ; 47,62 \%)$, apesar da menor positividade verificada entre os astrocitomas de grau II. A positividade para BCL-2 e BAX na totalidade dos tumores astrocíticos investigados foi de $43,26 \%$ e $24,67 \%$, respectivamente, sendo a porcentagem de casos imunopositivos para BCL-2 superior à dos imunopositivos para BAX em todas as graduações tumorais. Tais proteínas não foram evidenciadas entre as amostras não-tumorais pesquisadas (Figura 2).

Observou-se propensão ao acréscimo dos índices de marcação para BCL-2 (니 [4,3; 6,57; 8,71; 16,85] e H [10,84; $14,42 ; 18,85 ; 27,85])$, de acordo com a graduação histopatológica dos tumores astrocíticos, enquanto os valores para BAX (LI $[5 ; 0,57 ; 9,28 ; 9,38]$ e H $[11,53 ; 0,57 ; 17,14$; $11,66])$ demonstraram escores semelhantes nas diferentes gradações, exceto pelos menores índices novamente verificados para os tumores de grau II (Figura 3).

As marcações para BCL-2 (LI) e BAX (LI) manifestaram correlação significativa com a graduação dos astrocitomas
( $p<0,05$; teste $\mathrm{H}$ de Kruskal-Wallis), sendo mais freqüente a detecção dessas moléculas nos tumores de grau IV em comparação com os de baixo grau (I e II) $(p<0,05$; teste U de Mann-Whitney). $O$ balanço qualiquantitativo entre os escores de marcação verificados para BCL-2 (estímulo antiapoptótico) e BAX (estímulo pró-apoptótico) revelou tendência crescente à sobrevida celular, de acordo com a progressão maligna dos tumores astrocíticos (Figura 4).

\section{Discussão}

No presente estudo, tanto a porcentagem de casos positivos quanto os escores médios de marcação (LI e H) para a proteína antiapoptótica $B C L-2$ demonstraram tendência de aumento, segundo a graduação dos tumores astrocíticos (Figuras 2 e 3), indicando a superexpressão dessa proteína como um evento freqüente nos astrocitomas e diretamente proporcional ao grau de malignidade tumoral. Fels et al.(9) haviam detectado propensão similar quanto à positividade para BCL-2 nos tumores astrocíticos de alto grau ( $48 \%$ no grau III; $51 \%$ no IV), ao passo que Ellison et al. ${ }^{(8)}$ descreveram inclinação oposta (44\% no grau II; $42 \%$ no III; $28 \%$ no IV). Recentemente, Strik et al. ${ }^{(22)}$ e Kraus et al. ${ }^{(15)}$ confirmaram a tendência de maior positividade entre os astrocitomas grau IV (94,6\% e $60,25 \%$, respectivamente), reforçando o perfil aqui reportado. Possíveis comparações semiquantitativas acerca da expressão de BCL-2 em tumores astrocíticos foram impossibilitadas pela inexistência de estudos anteriores
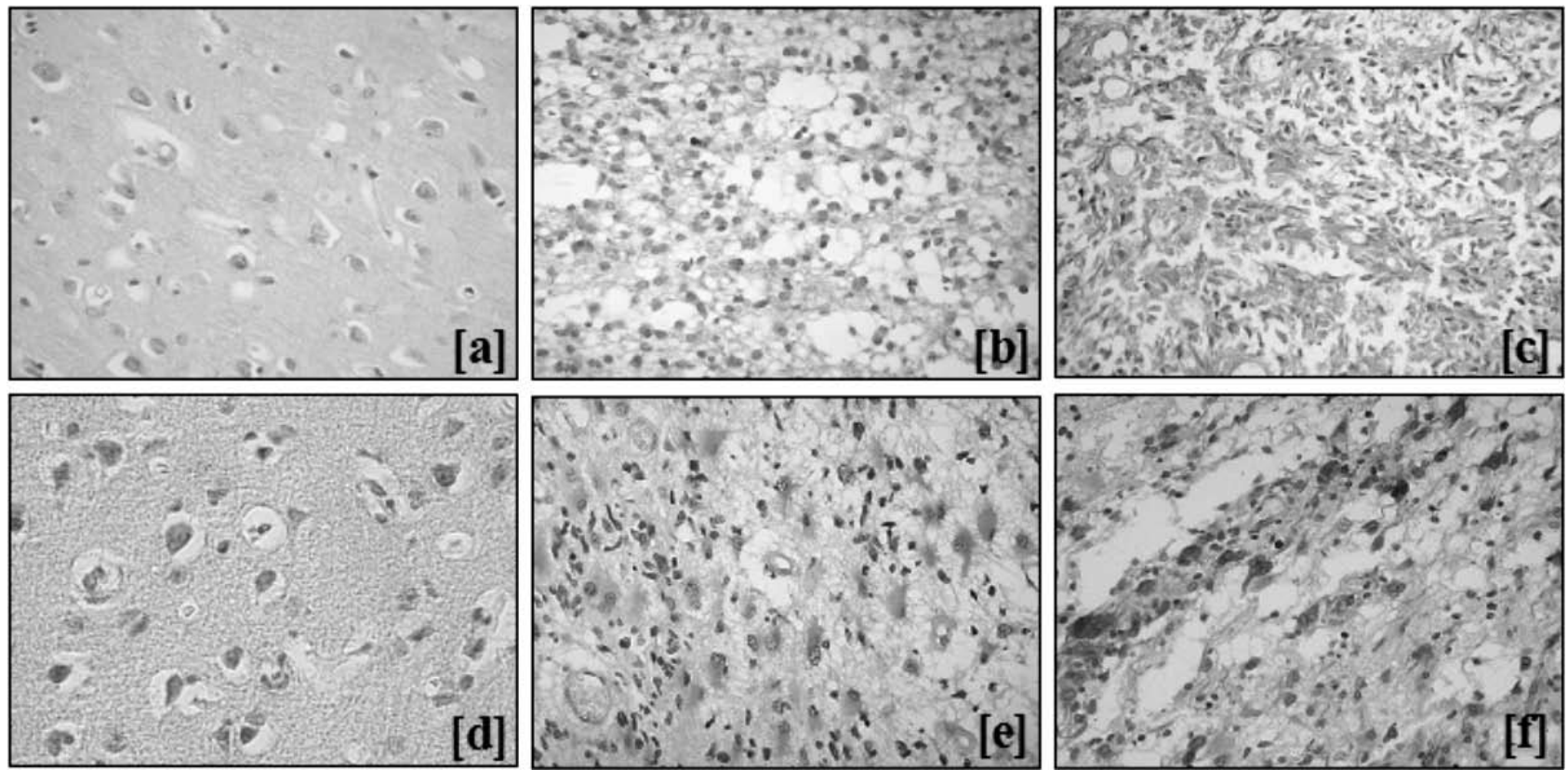

Figura 1 - Expressão das proteínas $B A X(a, b, c)$ e BCL-2 (d, e, f) detectadas por imuno-histoquímica (400x). [a] Córtex cerebral não-tumoral: ausência de marcação: [b] astrocitoma grau I (OMS): marcação moderada; [c] astrocitoma grau IV (OMS): marcação intensa; [d] córtex cerebral não-tumoral: ausência de marcação; [e] astrocitoma grau III (OMS): marcação moderada, predominante em células gemistocíticas; [f] astrocitoma grau I (OMS): marcação intensa 
Histopatologia, epidemiologia geral e achados imuno-histoquímicos referentes aos casos avaliados

\begin{tabular}{|c|c|c|c|c|c|c|c|c|c|c|}
\hline \multirow[t]{3}{*}{ Caso } & \multirow{2}{*}{\multicolumn{2}{|c|}{ Histopatologia }} & \multirow{2}{*}{\multicolumn{2}{|c|}{ Epidemiologia }} & \multicolumn{6}{|c|}{ Marcadores: apoptose } \\
\hline & & & & & \multicolumn{3}{|c|}{ BCL-2 } & \multicolumn{3}{|c|}{ BAX } \\
\hline & Grau (OMS) & Subtipo & Idade & Sexo & H-score & LI & Padrão & H-score & LI & Padrão \\
\hline NT01 & NT & - & 48 & M & 0 & 0 & - & 0 & 0 & - \\
\hline NT02 & NT & - & 14 & M & 0 & 0 & - & 0 & 0 & - \\
\hline NT03 & NT & - & 55 & $\mathrm{~F}$ & 0 & 0 & - & 0 & 0 & - \\
\hline NT04 & NT & - & 15 & $\mathrm{~F}$ & 0 & 0 & - & 0 & 0 & - \\
\hline NT05 & NT & - & 57 & $\mathrm{~F}$ & 0 & 0 & - & 0 & 0 & - \\
\hline T01 & $\mathrm{I}$ & Pilocítico & 10 & M & 3 & 3 & $\mathrm{~F}$ & 3 & 3 & $\mathrm{~F}$ \\
\hline T02 & I & Pilocítico & 19 & M & 70 & 25 & $\mathrm{D}$ & 0 & 0 & - \\
\hline T03 & I & Pilocítico & 34 & $\mathrm{~F}$ & 5 & 5 & $\mathrm{D}$ & 2 & 2 & $\mathrm{~F}$ \\
\hline T04 & I & Pilocítico & 6 & M & 3 & 3 & MF & 0 & 0 & - \\
\hline T05 & I & Pilocítico & 17 & $\mathrm{~F}$ & 60 & 20 & MF & 0 & 0 & - \\
\hline T06 & I & Pilocítico & 4 & $\mathrm{~F}$ & 0 & 0 & - & 0 & 0 & - \\
\hline T07 & I & Pilocítico & 16 & M & 0 & 0 & - & 0 & 0 & - \\
\hline T08 & I & Pilocítico & 4 & $\mathrm{~F}$ & 0 & 0 & - & 0 & 0 & - \\
\hline T09 & I & Pilocítico & 14 & M & 0 & 0 & - & 0 & 0 & - \\
\hline $\mathrm{T} 10$ & I & Pilocítico & 3 & M & 0 & 0 & - & 0 & 0 & - \\
\hline T11 & I & Pilocítico & - & $\mathrm{F}$ & 0 & 0 & - & 70 & 25 & D \\
\hline $\mathrm{T} 12$ & I & Pilocítico & 42 & M & 0 & 0 & - & 0 & 0 & - \\
\hline $\mathrm{T} 13$ & I & Pilocítico & 13 & $\mathrm{~F}$ & 0 & 0 & - & 75 & 35 & $\mathrm{D}$ \\
\hline $\mathrm{T} 14$ & II & Fibrilar & 56 & M & 3 & 3 & $\mathrm{D}$ & 0 & 0 & - \\
\hline T15 & II & Gemistocítico & 34 & $\mathrm{~F}$ & 8 & 4 & MF & 0 & 0 & - \\
\hline $\mathrm{T} 16$ & II & Fibrilar & 23 & M & 6 & 2 & MF & 0 & 0 & - \\
\hline T17 & II & Fibrilar & 36 & M & 75 & 30 & MF & 0 & 0 & - \\
\hline T18 & II & Fibrilar & 47 & M & 28 & 10 & $\mathrm{D}$ & 8 & 8 & $\mathrm{D}$ \\
\hline T19 & II & Fibrilar & 4 & M & 25 & 15 & MF & 0 & 0 & - \\
\hline $\mathrm{T} 20$ & II & Fibrilar & 2 & M & 22 & 8 & $\mathrm{D}$ & 0 & 0 & - \\
\hline T21 & II & Fibrilar & 37 & $\mathrm{~F}$ & 35 & 20 & MF & 0 & 0 & - \\
\hline $\mathrm{T} 22$ & II & Fibrilar & 33 & M & 0 & 0 & - & 0 & 0 & - \\
\hline $\mathrm{T} 23$ & II & Fibrilar & 67 & M & 0 & 0 & - & 0 & 0 & - \\
\hline T24 & II & Fibrilar & 23 & $\mathrm{~F}$ & 0 & 0 & - & 0 & 0 & - \\
\hline T25 & II & Fibrilar & 48 & M & 0 & 0 & - & 0 & 0 & - \\
\hline T26 & II & Fibrilar & 43 & M & 0 & 0 & - & 0 & 0 & - \\
\hline T27 & II & Fibrilar & 28 & $\mathrm{~F}$ & 0 & 0 & - & 0 & 0 & - \\
\hline T28 & III & Anaplásico & 71 & M & 11 & 8 & $\mathrm{D}$ & 0 & 0 & - \\
\hline Т29 & III & Anaplásico & 56 & M & 30 & 15 & $D$ & 0 & 0 & - \\
\hline T30 & III & Anaplásico & 40 & M & 8 & 4 & $\mathrm{D}$ & 0 & 0 & - \\
\hline $\mathrm{T} 31$ & III & Anaplásico & 62 & $\mathrm{~F}$ & 8 & 4 & $\mathrm{D}$ & 90 & 45 & $\mathrm{D}$ \\
\hline Т32 & III & Anaplásico & 28 & $\mathrm{~F}$ & 75 & 30 & D & 0 & 0 & - \\
\hline
\end{tabular}




\begin{tabular}{|c|c|c|c|c|c|c|c|c|c|c|}
\hline T33 & III & Anaplásico & 22 & M & 0 & 0 & - & 0 & 0 & - \\
\hline T34 & III & Anaplásico & 27 & M & 0 & 0 & - & 30 & 20 & D \\
\hline T35 & IV & Glioblastoma & 5 & $\mathrm{~F}$ & 13 & 10 & $\mathrm{D}$ & 0 & 0 & - \\
\hline T36 & IV & Glioblastoma & 57 & M & 150 & 80 & $\mathrm{~F}$ & 20 & 15 & MF \\
\hline T37 & IV & Glioblastoma & 43 & $\mathrm{~F}$ & 11 & 8 & MF & 0 & 0 & - \\
\hline T38 & IV & Glioblastoma & 62 & M & 5 & 5 & $\mathrm{D}$ & 0 & 0 & - \\
\hline T39 & IV & Glioblastoma & 32 & M & 0 & 0 & - & 30 & 20 & MF \\
\hline T40 & IV & Glioblastoma & 50 & M & 8 & 8 & MF & 15 & 15 & MF \\
\hline T41 & IV & Glioblastoma & - & $\mathrm{F}$ & 110 & 60 & $\mathrm{D}$ & 0 & 0 & - \\
\hline T42 & IV & Glioblastoma & 34 & M & 40 & 25 & $\mathrm{~F}$ & 0 & 0 & - \\
\hline T43 & IV & Glioblastoma & 54 & M & 0 & 0 & - & 13 & 10 & $\mathrm{~F}$ \\
\hline T44 & IV & Glioblastoma & 81 & $\mathrm{~F}$ & 15 & 15 & D & 0 & 0 & - \\
\hline T45 & IV & Glioblastoma & 72 & $\mathrm{~F}$ & 40 & 25 & D & 30 & 25 & D \\
\hline T46 & IV & Glioblastoma & 44 & M & 40 & 30 & $\mathrm{D}$ & 30 & 20 & $\mathrm{D}$ \\
\hline T47 & IV & Glioblastoma & 62 & $\mathrm{~F}$ & 0 & 0 & - & 15 & 15 & MF \\
\hline T48 & IV & Glioblastoma & 43 & M & 0 & 0 & - & 2 & 2 & $\mathrm{D}$ \\
\hline T49 & IV & Glioblastoma & 55 & M & 10 & 10 & $\mathrm{D}$ & 0 & 0 & - \\
\hline $\mathrm{T} 50$ & IV & Glioblastoma & 53 & M & 3 & 3 & $\mathrm{D}$ & 0 & 0 & - \\
\hline $\mathrm{T} 51$ & IV & Glioblastoma & 50 & M & 50 & 30 & $\mathrm{D}$ & 40 & 30 & $\mathrm{D}$ \\
\hline T52 & IV & Glioblastoma & 51 & $\mathrm{~F}$ & 20 & 15 & $\mathrm{D}$ & 35 & 30 & MF \\
\hline $\mathrm{T} 53$ & IV & Glioblastoma & 65 & M & 0 & 0 & - & 15 & 15 & MF \\
\hline T54 & IV & Glioblastoma & 55 & M & 65 & 25 & $\mathrm{D}$ & 0 & 0 & - \\
\hline $\mathrm{T} 55$ & IV & Glioblastoma & 55 & M & 5 & 5 & $\mathrm{D}$ & 0 & 0 & - \\
\hline
\end{tabular}

NT: não-tumoral; T: tumoral; idade: em anos completos; M: masculino; F: feminino; F: focal; MF: multifocal; D: difuso; -: ignorado/não procede.

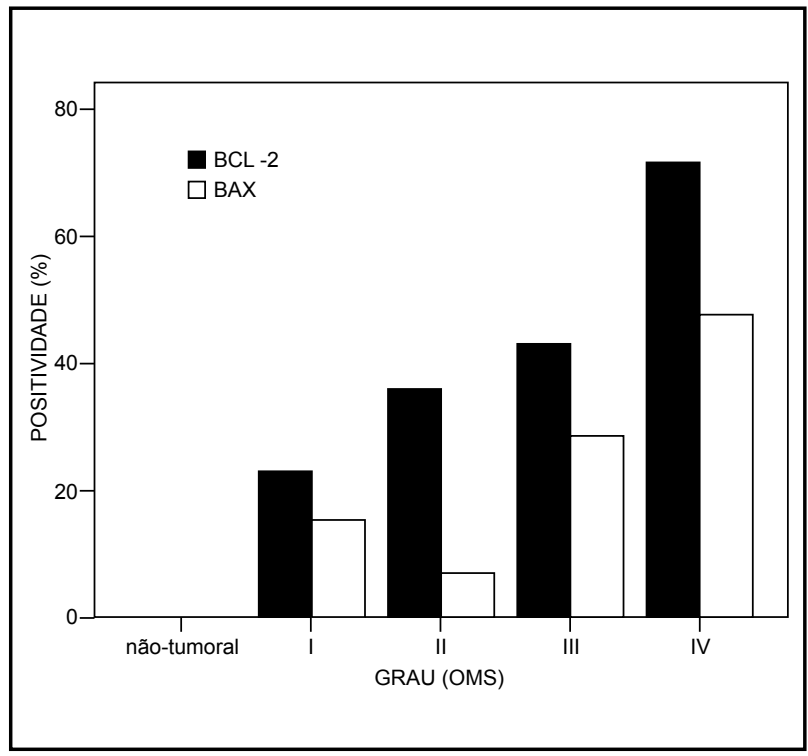

Figura 2 - Percentuais de positividade imuno-histoquímica para as proteínas $B C L-2$ e BAX segundo a classificação histológica dos casos avaliados

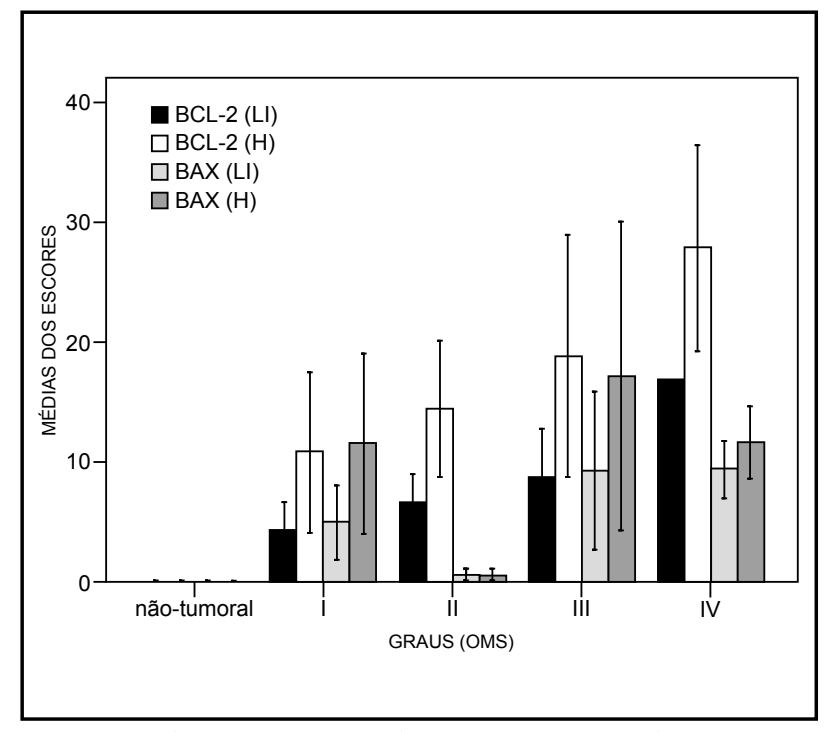

Figura 3 - Médias dos escores atribuídos à expressão das proteínas $B C L-2$ e $B A X$ (Ll e H) detectada por imuno-histoquímica segundo a classificação histológica dos casos avaliados. LI: labelling index; $\mathrm{H}$ : $\mathrm{H}$-score 


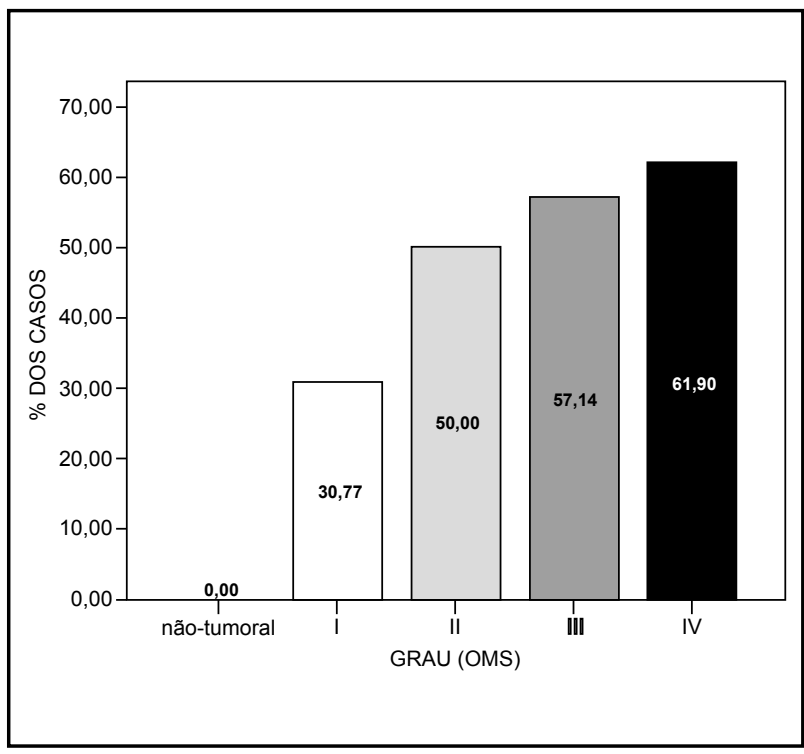

Figura 4 - Distribuição percentual das diferentes classificações histológicas segundo a tendência à sobrevida estimada pelo equilíbrio entre as expressões das proteínas BCL-2 e BAX detectadas por imuno-histoquímica

que apresentassem escores de marcação compatíveis com os aqui realizados, reafirmando o ineditismo da corrente investigação.

Com relação à expressão da proteína pró-apoptótica BAX, demonstraram-se propensão ao acréscimo na positividade e relativa constância entre as médias de marcação (LI e H), conforme a graduação dos tumores astrocíticos, excetuando-se a relativa redução verificada em todos os valores referentes aos astrocitomas grau II (Figuras 2 e 3 ). Tais resultados confirmam a superexpressão de BAX como decorrente do processo de tumoração nos astrocitomas, sendo tal fenômeno cada vez mais freqüente conforme a malignidade desses tumores. Quanto à intrigante redução da marcação para BAX nos tumores de grau II, admitese que particularidades referentes à histogênese dessa classe tumoral possam provocar variações na expressão de moléculas relacionadas à apoptose ${ }^{(10)}$, consolidando as diferenças entre os tumores do grau I estudados (astrocitomas pilocíticos) e os astrocitomas grau II, esses últimos sabidamente propensos à progressão para fenótipos mais malignos $^{(13)}$. Todavia essas variações podem ser mais bem compreendidas quando avaliadas ante o equilíbrio entre as tendências pró e antiapoptótica ${ }^{(25)}$. Os escassos estudos até então publicados acerca da expressão imuno-histoquímica de BAX nos tumores astrocíticos relatam apenas a alta freqüência da detecção de BAX nos glioblastomas (78\%(22), $\left.94 \%(4), 98 \%{ }^{(14)}\right)$, diferentemente da moderada positividade reportada no presente estudo $(47,62 \%)$.

A despeito da ausência de significância estatística verificada entre os índices de marcação (LI e H) para BCL-2 e BAX na análise seqüencial (teste $U$ ) das diferentes gradações dos astrocitomas, o exame do conjunto dos valores (teste $\mathrm{H}$ ) relativos à fração de células positivas (LI) para essas proteínas demonstrou correlação significativa com o grau histopatológico. Tal distinção foi reforçada pela expressiva superioridade dos escores para BCL-2 e BAX nos tumores de grau IV (glioblastomas) em relação aos de baixo grau (I e II) (teste $U$ ). Diante do exposto, notabilizou-se o aumento paralelo na detecção das proteínas BAX e BCL-2, conforme a gradação dos astrocitomas (notadamente entre os de baixo e alto graus), sugerindo mecanismos de co-regulação entre a expressão dessas proteínas durante a progressão maligna dos tumores astrocíticos ${ }^{(18)}$.

Além disso, através da comparação quantitativa entre os índices de marcação (LI) das proteínas BCL-2 e BAX, foi demonstrada crescente orientação à sobrevida celular consoante a progressão dos tumores astrocíticos (Figura 4). Acredita-se que essa diminuição gradual do estímulo apoptótico, associada ao pressuposto aumento progressivo do incentivo proliferativo, resulte na promoção cada vez maior das células mais anaplásicas (mais alteradas geneticamente), contribuindo para a evolução do fenótipo maligno dos astrocitomas ${ }^{(23)}$. Apesar disso, nenhuma correlação prognóstica categórica foi detectada a partir da expressão das proteínas BCL-2 e BAX nos tumores astrocíticos até este momento ${ }^{(9,10,21,22)}$.

Por fim, a constatação do aumento na expressão da proteína antiapoptótica BCL-2 conforme a progressão dos tumores astrocíticos, resultando em crescente tendência à sobrevida celular, abre espaço para abordagens que promovam o bloqueio transcricional dessa proteína e, assim, estimulem o mecanismo apoptótico. Neste sentido, Zhu et al.(24) reportaram considerável inibição do crescimento tumoral, completa perda do potencial tumoral e significativo incremento da sensibilidade à cisplatina em culturas de astrocitomas malignos humanos tratados com oligonucleotídeos antisense para BCL-2. Jiang et al. ${ }^{(12)}$ obtiveram semelhantes resultados com o uso de oligonucleotídeos antisense para $B C L-2 / B C L-x_{L}$ (biespecíficos) nas linhagens de glioblastomas U87 e NS008. 


\section{Referências}

I. ALBERTS, B. et al. Molecular biology of the cell. 4. ed. New York: Garland Science, 2002.

2. AMARANTE-MENDES, G. P.; GREEN, D. R. The regulation of apoptotic cell death. Braz J Med Biol Res, v. 32, p. 1053 $61,1999$.

3. ANTONSSON, B.; MARTINOU, J-C. The BCL-2 protein family. Exp Cell Res, v. 256, p. 50-7, 2000.

4. CARTRON, P. F. et al. Nonredundant role of BAX and BAK in Bid-mediated apoptosis. Mol Cell Biol, v. 23, n. I3, p. 4701 12, 2003.

5. COTRAN, R. S.; KUMAR, V.; COLLINS, S. L. (eds.). Neoplasia. In: ROBBINS. Patologia estrutural e funcional. 6. ed. Rio de Janeiro: Guanabara Koogan, 2000. Cap. 8, p. 233-95.

6. DESAGHER, S.; MARTINOU, J-C. Mitochondria as the central control point of apoptosis. Trends Cell Biol, v. I0, p. 36977. 2000.

7. ELLISON, D. et al. Neuropathology: a reference text of CNS pathology. 2. ed. Los Angeles: Mosby, 2004.

8. ELLISON, D.W. et al.Apoptosis in cerebral astrocytic tumours and its relationship to expression of the $\mathrm{Bcl}-2$ and $\mathrm{p} 53$ proteins Neuropathol Appl Neurobiol, v. 21, n. 4, p. 352-6I, 1995.

9. FELS, C. et al. BCL-2 expression in higher-grade human glioma: a clinical and experimental study.J Neuro-Oncol, v. 48, n. 3, p. 207-16, 2000

10. HARA, A. et al. Expression of Bax and BCL-2 proteins, regulators of programmed cell death, in human brain tumors. Neurol Res, v. 19, n. 6, p. 623-8, 1997.

I I. HSU, S. M.; RAINE, L.; FANGER, H. Use of avidin-biotin peroxidase complex $(A B C)$ in immunoperoxidade techniques: a comparison between $A B C$ and unlabled antibody (PAP) procedures. J Histochem Cytochem, v. 29 p. 577-80, 1981.

12. JIANG, Z:; ZHENG, X.; RICH, K. M. Down-regulation of BCL-2 and $B C L-x L$ expression with bispecific antisense treatment in glioblastoma cell lines induce cell death. J Neurochem, v. 84, n. 2, p. 273-81, 2003.

13. KLEIHUES, P. et al. The WHO classification of tumours of the nervous system. I Neuropathol Exp Neurol, v. 6I, n. 3, p. 215-25, 2002

14. KRAJEWSKI, S. et al. Immunohistochemical analysis of BCL$2, B C L-X, M C L-I$ and $B A X$ in tumors of central and peripheral nervous system origin. Am J Pathol, v. I50, n. 3, p. 805-14, 1997

15. KRAUS, J. A. et al. TP53 gene mutations, nuclear p53 accumulation, expression of Waf/p21, Bcl-2, and CD95 (APO-I/Fas) proteins are not prognostic factors in de novo glioblastoma multiforme. J Neurooncol, v. 52, n. 3, p. 263-72, 2001.

16. LANDBERG, G.; ROSS, G. Proliferating cell nuclear antigen and Ki-67 antigen expression in human haematopoietic cells during growth stimulation and differentiation. Cell Prolif, v. 26, p. 427-37, 1993.

17. LANTOS, P. L.; ROSENBLUM, M. K.; KLEIHUES, P. Tumours of the nervous system. In: GRAHAN, D. I.; LANTOS, P. L. (eds.). Greenfield's Neuropathology. 7. ed. Glasgow: Arnold Publishers, 2002. vol. 2.

18. MARTIN, S. et al. Expression of BCL-2, BAX and BCL-x| in human gliomas: a re-appraisal. J Neurooncol, v. 52, n. 2, p. |29-39, 200|.

19. McCARTY Jr., K. S. et al. Correlation of biochemical and immunohistochemical methods using monoclonal antireceptor antibodies. Arch Pathol Lab Med, v. 109, n. 8 , p. 7I6-2I, 1985

20. PELENGARIS, S.; KHAN, M.; EVAN, G. c-Myc: more than just a matter of life and death. Nat Rev Cancer, v. 2, n. 10, p. 764-76, 2002.

21. RIEGER, L. et al. BCL-2 family protein expression in human malignant glioma: a clinical-pathological correlative study. J Neurol Sci, v. I55, n. I, p. 69-75, 1998.

22. STRIK, $H$. et al. BCL-2 family protein expression in initial and recurrent glioblastomas: modulation by radiochemotherapy. J Neurol Neurosurg Psychiatry, v. 67, n. 6, p.763-8, 1999.

23. YU, S. et al. Relationship of BCL-2 gene expression with cell proliferation and apoptosis in human gliomas. Zhonghua Bing Li Xue Za Zhi, v. 29, n. I, p. I2-5, 2000.

24. ZHU, C. J. et al. Expression of antisense BCL-2 cDNA abolishes tumorigenicity and enhances chemosensitivity of human malignant glioma cells. J Neurosci Res, v. 74, n. I, p. 60-6, 2003.

25. ZÖRNIG, M. et al. Apoptosis regulators and their role in tumorigenesis. Biochim Biophys Acta, v. I55I, p. FI-F37, 2001 . 